\title{
Bi-mediated allylation of aldehydes in [bmim] [Br]: a mechanistic investigation
}

\author{
Mrunesh Koli ${ }^{1}$, Sucheta Chatterjee ${ }^{1}$, Subrata Chattopadhyay ${ }^{1}$ and Dibakar Goswami ${ }^{*}{ }^{1,2}$
}

\author{
Full Research Paper \\ Address: \\ ${ }^{1}$ Bio-Organic Division, Bhabha Atomic Research Centre, Mumbai - \\ 400 085, India and ${ }^{2}$ Homi Bhabha National Institute, Training School \\ Complex, Anushakti Nagar, Mumbai - 400 094, India \\ Email: \\ Dibakar Goswami* - dibakarg@barc.gov.in \\ * Corresponding author \\ Keywords: \\ allylation; bismuth; [bmim][Br]; ionic liquid
}

\author{
Beilstein J. Org. Chem. 2018, 14, 2198-2203. \\ doi:10.3762/bjoc. 14.193 \\ Received: 25 June 2018 \\ Accepted: 03 August 2018 \\ Published: 22 August 2018 \\ Associate Editor: L. Vaccaro \\ (c) 2018 Koli et al.; licensee Beilstein-Institut. \\ License and terms: see end of document.
}

\begin{abstract}
The inexpensive room temperature ionic liquid (RTIL), [bmim][Br] has been found to be a superior medium for the Bi-mediated Barbier-type allylation of aldehydes compared to other conventional solvents. It plays the dual role of a solvent and a metal activator enabling higher yields of the products in a shorter reaction time using stoichiometric/near-stoichiometric amounts of reagents. Plausibly, [bmim] $[\mathrm{Br}]$ activates Bi metal by a charge transfer mechanism. The ${ }^{1} \mathrm{H}$ VT-NMR studies suggested that both the allylating species, allylbismuth dibromide and diallylbismuth bromide, are generated in situ.
\end{abstract}

\section{Introduction}

The metal-mediated Barbier-type allylation of aldehydes has drawn considerable attention, because the resultant homoallylic alcohols are versatile intermediates for natural product synthesis [1-7]. The reaction, carried out in organic solvents, water, mixed solvent systems and room temperature ionic liquids (RTILs) is also ideal for probing in situ formation of different allylmetal species in solution, their stability and reactivity towards electrophiles [8-10]. Despite extensive investigation, several key factors of the reaction have not been adequately addressed. In modern era, the development of green chemical routes has become inevitable for sustainable technologies. To this end, RTILs are conceived as eco-friendly solvents due to their low vapor pressure, high stability towards air, moisture and heat, ability to dissolve various substrates, and their reus- ability [11-14]. However, issues such as use of large excess of the reagents, solvents, metals and toxic metal activators such as acids or fluorides are the major limitations of the reported protocols of this reaction [15-18]. Other methods such as Rieke's activation [19], metal-graphite [20] etc. are also tedious and not ideal for green chemistry. The use of a second metal with lower reduction potential than the active metals could not reduce the amounts of disposable metallic wastes [21,22]. Since most of the in situ-generated allylmetals are hydrolytically unstable, a large excess of reagents is used for carrying out the reaction in water $[23,24]$.

Although several metals have been used for the reaction, those with $\mathrm{Zn}$, In and $\mathrm{Sn}$ are more widely investigated $[1,25]$. Howev- 
er, $\mathrm{Bi}$ is cheaper, less toxic [26], and has more metallic character [27]. Previously, the Bi-mediated Barbier-type allylations of carbonyls have been reported in organic solvents [28-30], water [31] or under solvent-free conditions [32,33]. The solvent free synthetic procedure required a large excess (4-8 equiv) of Bi metal [33] whereas, the reactions in water or in organic solvents required either aqueous $\mathrm{KF}$ [31] or aqueous $\mathrm{HBr}[34]$ as the metal activator. As an alternative, $\mathrm{Xu}$ et al. found nano-Bi to be more effective than regular Bi-powder, although this method had an intrinsic difficulty of preparing Bi-nanoparticles via reduction of Bi(III) salts [35]. These apart, combinations of $\mathrm{Bi}(\mathrm{III})$ salts with reducing metals, e.g., $\mathrm{Mg}^{-\mathrm{BiCl}_{3}}$ [36], $\mathrm{Fe}-\mathrm{BiCl}_{3}$ or $\mathrm{Zn}-\mathrm{BiCl}_{3}$ [30], and $\mathrm{Al}-\mathrm{BiCl}_{3}$ [37] have been used. Aqueous $\mathrm{NH}_{4} \mathrm{Cl}$ was also employed as an addi- tive in the $\mathrm{Al} / \mathrm{BiCl}_{3}$ mediated allylation of carbonyls in aqueous THF [38].

\section{Results and Discussion}

Initially, we screened different solvents and metal activators (chemical additives and ultrasonication) for the Bi-mediated allylation of benzaldehyde (1a), as the model substrate with commercially available and inexpensive allyl bromide (Scheme 1) at room temperature $\left(25^{\circ} \mathrm{C}\right)$ [39-42]. The results are shown in Table 1. As reported earlier [30], the reaction carried out in DMF took a long time for completion and gave the product $2 \mathrm{a}$ with a moderate yield (Table 1, entry 1 ). Increasing the amounts of $\mathrm{Bi}$ and allyl bromide did not improve the reaction outcome (Table 1, entry 2). Allylations in other organic

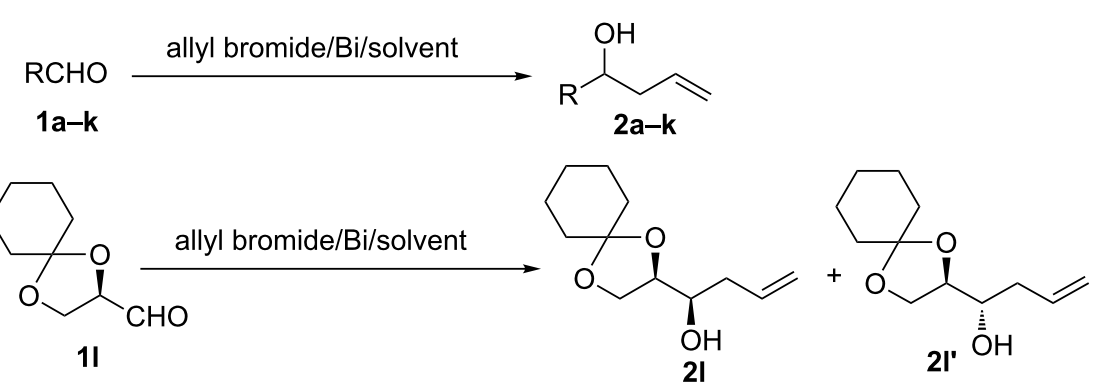

Scheme 1: Bi-mediated allylation of aldehydes.

\begin{tabular}{|c|c|c|c|c|c|c|}
\hline entry & allyl bromide (equiv) & $\mathrm{Bi}$ (equiv) & solvent & additive & time (h) & yield of $\mathbf{2} a^{b}$ \\
\hline 1 & 1.5 & 1.5 & DMF & - & 12 & 65 \\
\hline 2 & 2.5 & 2.0 & DMF & - & 12 & 67 \\
\hline 3 & 2.5 & 2.0 & $\mathrm{MeCN}$ & - & 12 & 52 \\
\hline 4 & 2.5 & 2.0 & $\mathrm{MeCN}$ & - & $10^{d}$ & 55 \\
\hline 5 & 2.5 & 2.0 & $\mathrm{MeCN}$ & $\mathrm{KF}^{\mathrm{C}}$ & 12 & 62 \\
\hline 6 & 2.5 & 2.0 & THF & - & 10 & 56 \\
\hline 7 & 2.5 & 2.0 & THF & - & $12^{d}$ & 58 \\
\hline 8 & 2.5 & 2.0 & THF & $\mathrm{KF}^{\mathrm{c}}$ & 12 & 40 \\
\hline 9 & 2.5 & 2.0 & $\mathrm{THF}: \mathrm{H}_{2} \mathrm{O}^{\mathrm{e}}$ & - & 14 & 60 \\
\hline 10 & 2.5 & 2.0 & $\mathrm{THF}: \mathrm{H}_{2} \mathrm{O}^{\mathrm{e}}$ & - & $14^{d}$ & 65 \\
\hline 11 & 2.5 & 2.0 & $\mathrm{H}_{2} \mathrm{O}$ & - & 11 & 45 \\
\hline 12 & 2.5 & 2.0 & $\mathrm{H}_{2} \mathrm{O}$ & - & $10^{d}$ & 48 \\
\hline 13 & 2.5 & 2.0 & $\mathrm{H}_{2} \mathrm{O}$ & $\mathrm{KF}^{\mathrm{C}}$ & 3 & 72 \\
\hline 14 & 2.5 & 2.0 & {$[\mathrm{bmim}]\left[\mathrm{PF}_{6}\right]$} & - & 14 & 41 \\
\hline 15 & 2.5 & 2.0 & {$[\mathrm{bmim}]\left[\mathrm{BF}_{4}\right]$} & - & $N R^{f}$ & $N R^{f}$ \\
\hline 16 & 1.2 & 1.0 & [bmim][Br] & - & 3 & 88 \\
\hline 17 & 1.2 & 1.0 & {$[\mathrm{bmim}][\mathrm{Br}]^{\mathrm{h}}$} & - & 12 & $N R^{f}$ \\
\hline 18 & 1.2 & 1.0 & {$[\mathrm{bmmim}][\mathrm{Br}]^{\mathrm{g}}$} & - & 12 & $N R^{f}$ \\
\hline
\end{tabular}

aThe reactions were carried out at $3 \mathrm{mmol}$ scale as detailed in the experimental section. ${ }^{\mathrm{b}}$ Isolated yield. ${ }^{\mathrm{c}} 15 \mathrm{mmol} \mathrm{KF}$ was used. ${ }^{\mathrm{d}} \mathrm{Under}$ ultrasonic irradiation. ${ }^{\mathrm{T}} \mathrm{THF} / \mathrm{H}_{2} \mathrm{O}(1: 1, \mathrm{v} / \mathrm{v})$ was used. ${ }^{\mathrm{N} R} \mathrm{~N}$ : No reaction. ${ }^{9} 1$-Butyl-2,3-dimethylimidazolium bromide is abbreviated as [bmmim] $\left.\mathrm{Br}\right]$. ${ }^{\mathrm{h}}[\mathrm{bmim}][\mathrm{Br}]$ was used after overnight purging with $\mathrm{N}_{2}(\mathrm{~g})$. 
solvents such as $\mathrm{MeCN}$ and THF were inferior, and furnished 2a in lesser yields (Table 1, entries 3-8) even under metal activation by KF (Table 1, entries 5 and 8 ) or ultrasonication (Table 1, entries 4 and 7). Reduction in the amounts of Bi and allyl bromide under these conditions led to significantly poorer results (data not shown). The use of the mixed solvent THF/ $\mathrm{H}_{2} \mathrm{O}(1: 1, \mathrm{v} / \mathrm{v})$ at room temperature or under sonication increased the reaction time (14 h), but furnished 2a in similar yields (60-65\%) as obtained in DMF or MeCN-KF (Table 1, entries 9 and 10 vis-à-vis 2 and 4). In water, the reaction yield was modest (entry 11). Ultrasonication in water gave a similar result (entry 12), but activation with aqueous KF boosted the yield to $72 \%$ and reduced the reaction time ( $3 \mathrm{~h}$, Table 1 , entry 13). The reaction in $[\mathrm{bmim}]\left[\mathrm{PF}_{6}\right]$ was sluggish and furnished $\mathbf{2 a}$ in $41 \%$ yield after $14 \mathrm{~h}$ (Table 1, entry 14), but the commonly used RTIL, [bmim] $\left[\mathrm{BF}_{4}\right]$ was totally ineffective (Table 1, entry 15). True to our expectation, the reaction was very fast in [bmim][Br] and furnished 2a in $88 \%$ yield. Notably, the reaction proceeded to completion with almost stoichiometric amounts of allyl bromide ( 1.2 equiv) and Bi (1.0 equiv) in absence of any additional metal activator (Table 1, entry 16). In addition, as previously reported in case of crotylation [40], the allylation did not proceed in absence of oxygen (Table 1, entry 17), or when the C-2 imidazole proton was absent in the RTIL (in 1-butyl-2,3-dimethylimidazolium bromide ([bmmim][Br]), Table 1, entry 18). This result is significant, since, to the best of our knowledge, this is the first report of Bi-mediated allylation of aldehydes in an RTIL.

Taken together, the above data revealed that $[\mathrm{bmim}][\mathrm{Br}]$ may be best suited for the Bi-mediated allylation. To probe the gener- ality of the methodology, several aromatic and aliphatic aldehydes $\mathbf{1 b}-\mathbf{l}$ were subjected to Bi-mediated allylation in [bmim][Br] (Scheme 1, Table 2). The reactions with aromatic aldehydes, possessing both electron-withdrawing (1b-e) and electron-releasing (1f-h) substituents were complete within 3-6 h to furnish $\mathbf{2 b}-\mathbf{h}$ in appreciable yields (Table 2, entries 1-7). Steric hindrance was not detrimental to the yield of the reaction, as it was evident from the allylation of $1 \mathbf{e}$, bearing a substituent ortho to the aldehyde function (Table 2, entry 4). The aliphatic aldehydes $\mathbf{1 i}$ and $\mathbf{1} \mathbf{j}$ also reacted similarly to give the homoallylic alcohols $\mathbf{2} \mathbf{i}$ and $\mathbf{2} \mathbf{j}$, respectively, in $>86 \%$ yields (Table 2, entries 8 and 9). Allylation of the conjugated aldehyde $1 \mathbf{k}$ furnished the 1,2-addition product $\mathbf{2 k}$ exclusively, establishing chemoselectivity of the protocol (Table 2, entry 10$)$. With the chiral substrate $(R)-2,3-O$-cyclohexylideneglyceraldehyde (11), the anti-homoallylic alcohol 2l' was obtained as the major diastereomer (Table 2, entry 11), although the reaction diastereoselectivity was inferior to that by the Luche's protocol using $\mathrm{Zn}$ metal [42]. In all the reactions, the products were easily isolated by extracting the reaction mixture three times with $\mathrm{Et}_{2} \mathrm{O}$ followed by concentration in vacuo. The reactions were clean without any side-products and unreacted starting materials. We have reused [bmim] $[\mathrm{Br}]$ three times after discarding the metallic product, $\mathrm{BiOBr}$, settled at the bottom of the flask, without any significant effect (88-85\%) on the reaction yields.

Overall, the above results clearly established that allylation of a broad spectrum of aldehydes could be realized with $\mathrm{Bi}$ in $[\mathrm{bmim}][\mathrm{Br}]$ in high yields and short reaction times without any additional Bi-activator. The RTIL [bmim][Br] acted both as a solvent and a metal activator, conferring unprecedented advan-

\begin{tabular}{|c|c|c|c|c|c|c|c|}
\hline entry & substrate & $\mathrm{R}$ & allyl bromide (equiv) & $\mathrm{Bi}$ (equiv) & time (h) & product & yield ${ }^{\mathrm{b}}(\%)$ \\
\hline 1 & $1 b$ & $p-\mathrm{Br}-\mathrm{C}_{6} \mathrm{H}_{4}$ & 1.2 & 1.0 & 6 & $2 b$ & 86 \\
\hline 2 & $1 c$ & $p-\mathrm{NO}_{2}-\mathrm{C}_{6} \mathrm{H}_{4}$ & 1.2 & 1.0 & 3 & 2c & 84 \\
\hline 3 & $1 d$ & $m-\mathrm{NO}_{2}-\mathrm{C}_{6} \mathrm{H}_{4}$ & 1.2 & 1.0 & 3 & $2 d$ & 83 \\
\hline 4 & $1 e$ & $o-\mathrm{Cl}-\mathrm{C}_{6} \mathrm{H}_{4}$ & 1.2 & 1.0 & 3 & $2 e$ & 89 \\
\hline 5 & $1 f$ & $p-\mathrm{MeO}-\mathrm{C}_{6} \mathrm{H}_{4}$ & 1.2 & 1.0 & 6 & $2 f$ & 87 \\
\hline 6 & $1 \mathrm{~g}$ & $m-\mathrm{MeO}-\mathrm{C}_{6} \mathrm{H}_{4}$ & 1.2 & 1.0 & 6 & $2 g$ & 85 \\
\hline 7 & $1 \mathrm{~h}$ & $3,5-(\mathrm{MeO})_{2}-\mathrm{C}_{6} \mathrm{H}_{3}$ & 1.2 & 1.0 & 3 & $2 h$ & 91 \\
\hline 8 & $1 \mathrm{i}$ & $\mathrm{C}_{6} \mathrm{H}_{13}$ & 1.2 & 1.0 & 6 & $2 \mathbf{i}$ & 86 \\
\hline 9 & $1 \mathrm{j}$ & $\mathrm{C}_{5} \mathrm{H}_{11}$ & 1.2 & 1.0 & 3 & $2 \mathbf{j}$ & 90 \\
\hline 10 & $1 \mathrm{k}$ & $\mathrm{C}_{6} \mathrm{H}_{5} \mathrm{CH}=\mathrm{CH}$ & 1.2 & 1.0 & 3 & $2 k$ & 81 \\
\hline 11 & 11 & & 1.2 & 1.0 & 3 & $2 l+2 l^{\prime}$ & $\begin{array}{c}84 \\
(\text { syn/anti }=32: 68)^{c}\end{array}$ \\
\hline
\end{tabular}

aThe reactions were carried out at $3 \mathrm{mmol}$ scale using the same conditions as mentioned in Table 1, entry 16. b/solated yields of the products. 'Diastereomeric ratio determined is based on isolated yields of individual diastereomers. 
tages in the reaction. In other RTILs, the reaction was either not proceeding at all, or was very sluggish. The specific advantages provided by $[\mathrm{bmim}][\mathrm{Br}]$ prompted us for further mechanistic studies as discussed below.

\section{Mechanistic studies}

For this, we first probed the nature of the organometallic species responsible for the reaction using in situ ${ }^{1} \mathrm{H}$ NMR spectroscopy of the reaction mixture comprising of $\mathrm{Bi}$ metal $(1 \mathrm{mmol})$ and allyl bromide $(1.2 \mathrm{mmol})$ in [bmim] $[\mathrm{Br}]$. After stirring the mixture for $1 \mathrm{~h}$ at $25^{\circ} \mathrm{C}$, an aliquot was drawn. Its ${ }^{1} \mathrm{H}$ NMR spectrum, recorded in $\mathrm{CD}_{2} \mathrm{Cl}_{2}$ (Figure 1) showed a

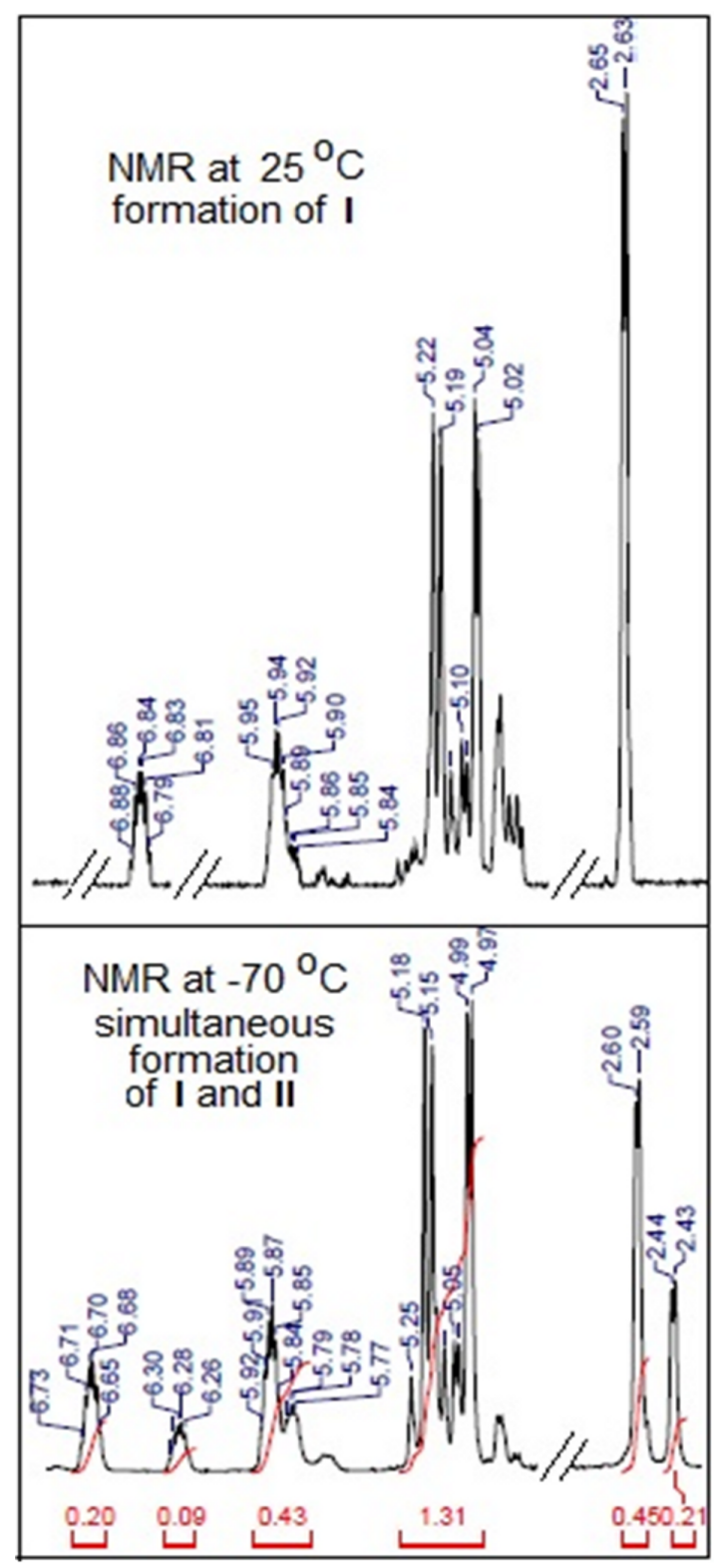

Figure 1: Partial ${ }^{1} \mathrm{H}$ NMR spectra (recorded at two temperatures) of the reaction mixture of allyl bromide and $\mathrm{Bi}$ stirred in [bmim] $[\mathrm{Br}]$ for $1 \mathrm{~h}$. doublet at $\delta 2.64 \mathrm{ppm}$, along with new olefinic multiplets at $\delta 6.82 \mathrm{ppm}$. When the ${ }^{1} \mathrm{H}$ NMR spectrum of the same aliquot was recorded at $-70{ }^{\circ} \mathrm{C}$, two doublets at $\delta 2.44$ and $\delta 2.60 \mathrm{ppm}$ appeared in 1:2 ratio (taking into account only the integral values in the ${ }^{1} \mathrm{H}$ NMR spectrum), along with new olefinic multiplets at $\delta 6.28$ and $6.70 \mathrm{ppm}$. Among the possible allylbismuth intermediates I-III (Figure 2), we excluded the possibility of formation of tris(allyl)bismuth (III), as the reported [38] doublet at $\delta 2.33 \mathrm{ppm}$ due to its allylic protons was absent in the ${ }^{1} \mathrm{H}$ NMR spectrum of the reaction mixture. Earlier, Jadhav et al. reported [38] formation of only species $\mathbf{I}$ in water, and characterized it from the allylic proton signals at $\delta 2.53 \mathrm{ppm}$ in its ${ }^{1} \mathrm{H}$ NMR spectrum recorded at an ambient temperature. More recently, Lichtenberg et al. [43] have shown that the ${ }^{1} \mathrm{H}$ NMR doublets $(\delta 2.45 \mathrm{ppm})$ due to the allylic protons of species II can be observed only by recording the ${ }^{1} \mathrm{H}$ NMR spectrum at a lower temperature $\left(-95^{\circ} \mathrm{C}\right)$, due to its fluxional behaviour at ambient temperature. These reports prompted us to infer the formation of both allylbismuth dibromide (I) and diallylbismuth bromide (II) in [bmim] [Br], where we could also characterize species II only by recording the NMR spectrum at $-70{ }^{\circ} \mathrm{C}$. The relative ratio of the integration originated from the allylic signals in ${ }^{1} \mathrm{H}$ NMR was 2:1 (Figure 1). However, since species I has only one allylic group compared to two in species II, stoichiometrically, species I and II are formed in 4:1 ratio. Nonetheless, the ${ }^{1} \mathrm{H}$ NMR spectral pattern clearly indicated formation of $\eta^{1}$-Bi-allyl coordination complexes. To the best of our knowledge, simultaneous formation of two allylbismuth species in any media is unprecedented.

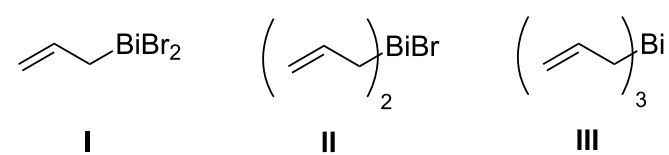

Figure 2: Structures of all the possible allylbismuth species.

To see the reactivity of the species I and II, benzaldehyde (1a) was added at $-70{ }^{\circ} \mathrm{C}$ to the stirred mixture of $\mathrm{Bi}$ and allyl bromide in $[\mathrm{bmim}][\mathrm{Br}]$, and the reaction was followed by ${ }^{1} \mathrm{H}$ NMR spectroscopy. However, the peaks corresponding to species I and II, observed at $-70{ }^{\circ} \mathrm{C}$, did not disappear immediately. Probably, benzaldehyde (1a) did not react at such a low temperature. Additionally, when the temperature was increased stepwise from $-70{ }^{\circ} \mathrm{C}$ to $0{ }^{\circ} \mathrm{C}$, we did not observe any peak due to the formation of $2 \mathbf{a}$. This indicated the inertness of both the allylating species at zero or sub-zero temperature. However, when the mixture was brought to room temperature and stirred for further $30 \mathrm{~min}$, both I and II disappeared, along with the appearance of a triplet at $\delta 4.74 \mathrm{ppm}$, indicating the formation of 2a. Similar result was also obtained when benzaldehyde (1a) 
was added to the mixture at room temperature. These results clearly indicated that both $\mathbf{I}$ and II act as the active allylating species. However, at this point of time, we are unable to prove the relative reactivities of species $\mathbf{I}$ and II towards $\mathbf{1 a}$ in [bmim][Br]. In analogy to the report [38] describing $\mathbf{I}$ as the most active allylating species in water medium, we could only presume that $\mathbf{I}$ is also the most active species for the present protocol. Earlier, we could carry out the Ga-mediated allylation of aldehydes/ketones using a substoichiometric amount of $\mathrm{Ga}$ metal, due to the formation of diallyl-GaBr as the only active allylating species [35]. Given that one mole of II is expected to react with two moles of the aldehydes, the possibility of substoichiometric amount of Bi metal was explored using 1a as the substrate. However, the reaction was incomplete (data not shown), and required 1.0 equiv of Bi metal for completion.

As reported previously [40] in situ activation of Bi metal by [bmim] $[\mathrm{Br}]$ leading to the generation of an $\mathrm{NHC}$ along with $\mathrm{BiBr}$ (Scheme 2), was instrumental for the acceleration of the reaction. Eventually, an unstable NHC-Bi complex was formed, which, in presence of allyl bromide, produced both species I and II. It was also noticed that these reactions do not proceed either in a non-acidic RTIL viz. [bmim] $\left[\mathrm{BF}_{4}\right]$, or in absence of oxygen, or in [bmmim] [Br], where the $\mathrm{C}-2$ proton is absent. Together, these confirmed the essential role of the acidic $\mathrm{C} 2$ hydrogen and formation of superoxide radical in the reaction mechanism. In order to investigate whether species I and II are in equilibrium (perhaps with $\mathrm{BiBr}_{3}$ ), we added $\mathrm{BiBr}_{3}$ $(1 \mathrm{mmol})$ in a stirred mixture of $\mathrm{Bi}(1 \mathrm{mmol})$, allyl bromide $(1.2 \mathrm{mmol})$ in [bmim] [Br] $(2 \mathrm{~mL})$, stirred for additional $0.5 \mathrm{~h}$, and ${ }^{1} \mathrm{H}$ NMR spectrum of an aliquot taken from the reaction mixture was recorded in $\mathrm{CD}_{2} \mathrm{Cl}_{2}$ at $-70{ }^{\circ} \mathrm{C}$. However, no change in the stoichiometric ratio of species I and II was observed compared to what we observed in absence of added $\mathrm{BiBr}_{3}$. This invariably indicated that the species I and II are not in equilibrium, and are generated individually. The active species I and II reacted with the aldehydes to form the homoallylic alcohols, along with $\mathrm{BiOBr}$, confirmed by the powder $\mathrm{XRD}$ analysis of the light yellow precipitate. Earlier, it has been reported $[38,43]$ that the organobismuth halide generated in situ may act as a Lewis acid activator for the faster production of linear homoallylic alcohols. In the present case also, such a mechanism cannot be excluded.

\section{Conclusion}

In conclusion, we have demonstrated a metal-activator free, practically viable and operationally simple protocol for the Bi-mediated Barbier-type allylation of aldehydes in [bmim $][\mathrm{Br}]$ for the first time. To the best of our knowledge, Bi-mediated allylation of aldehydes has never been attempted in an RTIL. The generality of the protocol was established by subjecting a variety of aldehydes to allylation. Moreover, we have probed the active allylbismuth species generated in situ using ${ }^{1} \mathrm{H}$ VT-NMR, and have proposed a plausible mechanism for its formation.

\section{Supporting Information}

\section{Supporting Information File 1}

Experimental details and analytical data for products

2a-2l'.

[https://www.beilstein-journals.org/bjoc/content/ supplementary/1860-5397-14-193-S1.pdf]

\section{Supporting Information File 2}

NMR spectra for products $\mathbf{2 a}-\mathbf{2 l}$ ' and showing generation of species I and II in situ.

[https://www.beilstein-journals.org/bjoc/content/ supplementary/1860-5397-14-193-S2.pdf]

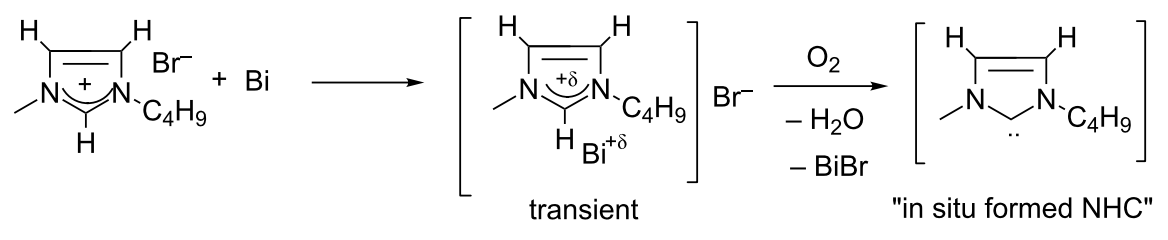

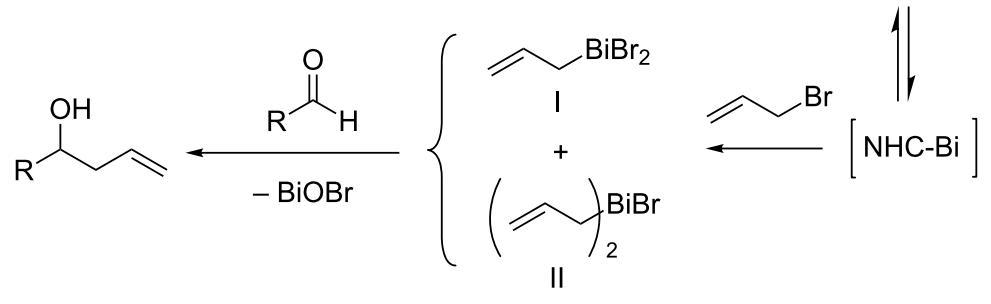




\section{ORCID ${ }^{\circledR}$ iDs}

Mrunesh Koli - https://orcid.org/0000-0003-4037-4739

\section{References}

1. Yus, M.; González-Gómez, J. C.; Foubelo, F. Chem. Rev. 2013, 113, 5595-5698. doi:10.1021/cr400008h

2. Smith, A. B., III; Adams, C. M.; Barbosa, S. A. L.; Degnan, A. P. J. Am. Chem. Soc. 2003, 125, 350-351. doi:10.1021/ja0289649

3. Hornberger, K. R.; Hamblet, C. L.; Leighton, J. L. J. Am. Chem. Soc. 2000, 122, 12894-12895. doi:10.1021/ja003593m

4. Kattuboina, A.; Kaur, P.; Timmons, C.; Li, G. Org. Lett. 2006, 8, 2771-2774. doi:10.1021/ol060828b and references cited therein.

5. Makita, N.; Hoshino, Y.; Yamamoto, H. Angew. Chem., Int. Ed. 2003, 42, 941-943. doi:10.1002/anie.200390250

6. Nicolaou, K. C.; Kim, D. W.; Baati, R. Angew. Chem., Int. Ed. 2002, 41, 3701-3704. doi:10.1002/1521-3773(20021004)41:19<3701::AID-ANIE3701>3.0.CO ;2-4

7. Goswami, D.; Sur, P.; Chattopadhyay, A.; Sharma, A.; Chattopadhyay, S. Synthesis 2011, 1626-1632. doi:10.1055/s-0030-1260014

8. Kundu, A.; Prabhakar, S.; Vairamani, M.; Roy, S. Organometallics 1997, 16, 4796-4799. doi:10.1021/om9704096

9. Dam, J. H.; Fristrup, P.; Madsen, R. J. Org. Chem. 2008, 73, 3228-3235. doi:10.1021/jo800180d

10. Koszinowski, K. J. Am. Chem. Soc. 2010, 132, 6032-6040. doi:10.1021/ja908101j

11. Nelson, W. M. In Green Chemistry; Anastas, P. T.; Williamson, T. C., Eds.; Oxford University Press: Oxford, 1998; p 200.

12. Hallett, J. P.; Welton, T. Chem. Rev. 2011, 111, 3508-3576. doi:10.1021/cr1003248

13. Welton, T. Chem. Rev. 1999, 99, 2071-2083. doi:10.1021/cr980032t

14. Wasserscheid, P.; Keim, W. Angew. Chem., Int. Ed. 2000, 39, 3772-3789.

doi:10.1002/1521-3773(20001103)39:21<3772::AID-ANIE3772>3.0.CO ;2-5

15. Shank, R. S.; Shechter, H. J. Org. Chem. 1959, 24, 1825-1826. doi:10.1021/j001093a630

16. LeGoff, E. J. Org. Chem. 1964, 29, 2048-2050. doi:10.1021/jo01030a529

17. Takai, K.; Ueda, T.; Hayashi, T.; Moriwake, T. Tetrahedron Lett. 1996, 37, 7049-7052. doi:10.1016/0040-4039(96)01548-1

18. Takai, K.; Ikawa, Y. Org. Lett. 2002, 4, 1727-1729. doi:10.1021/ol025784v

19. Rieke, R. D. Aldrichimica Acta 2000, 33, 52-60.

20. Fürstner, A. Active Metals: Preparation, Characterization, Application; VCH: Weinheim, 1996.

21. Preite, M. D.; Jorquera-Geroldi, H. A.; Pérez-Carvajal, A. ARKIVOC 2011, No. vii, 380-388. doi:10.3998/ark.5550190.0012.731

22. Araki, S.; Jin, S.-J.; Idou, S. Y.; Butsugan, Y. Bull. Chem. Soc. Jpn. 1992, 65, 1736-1738. doi:10.1246/bcsj.65.1736

23. Kamienski, C. W.; Esmay, D. L. J. Org. Chem. 1960, 25, 1807-1808. doi:10.1021/jo01080a035

24. Smith, W. N., Jr. J. Organomet. Chem. 1974, 82, 1-5. doi:10.1016/S0022-328X(00)80712-3

25. Kumar, D.; Vemula, S. R.; Balasubramanian, N.; Cook, G. R. Acc. Chem. Res. 2016, 49, 2169-2178. doi:10.1021/acs.accounts.6b00362
26. Sadler, P. J.; Li, H.; Sun, H. Coord. Chem. Rev. 1999, 185-186. doi:10.1016/S0010-8545(99)00018-1

27. Blomberg, C. The Barbier Reaction and Related One-Step Processes; Springer Science \& Business Media, 2012.

28. Wada, M.; Akiba, K.-y. Tetrahedron Lett. 1985, 26, 4211-4212. doi:10.1016/S0040-4039(00)98994-9

29. Miyoshi, N.; Nishio, M.; Murakami, S.; Fukuma, T.; Wada, M. Bull. Chem. Soc. Jpn. 2000, 73, 689-692. doi:10.1246/bcsj.73.689

30. Wada, M.; Ohki, H.; Akiba, K.-y. Bull. Chem. Soc. Jpn. 1990, 63, 1738-1747. doi:10.1246/bcsj.63.1738

31. Smith, K.; Lock, S.; El-Hiti, G. A.; Wada, M.; Miyoshi, N. Org. Biomol. Chem. 2004, 2, 935-938. doi:10.1039/b400179f

32. Andrews, P. C.; Peatt, A. C.; Raston, C. L. Green Chem. 2001, 3, 313-315. doi:10.1039/b108188h

33. Wada, S.; Hayashi, N.; Suzuki, H. Org. Biomol. Chem. 2003, 1 , 2160-2163. doi:10.1039/b303783e

34. Cintas, P. Activated Metals in Organic Synthesis; CRC Press, 1993.

35. Xu, X.; Zha, Z.; Miao, Q.; Wang, Z. Synlett 2004, 1171-1174. doi:10.1055/s-2004-822924

36. Wada, M.; Fukuma, T.; Morioka, M.; Takahashi, T.; Miyoshi, N. Tetrahedron Lett. 1997, 38, 8045-8048. doi:10.1016/S0040-4039(97)10105-8

37. Wada, M.; Ohki, H.; Akiba, K.-y. J. Chem. Soc., Chem. Commun. 1987, 708-709. doi:10.1039/C39870000708

38. Jadhav, B. D.; Pardeshi, S. K. Tetrahedron Lett. 2014, 55, 4948-4952. doi:10.1016/j.tetlet.2014.07.031

39. Goswami, D.; Chattopadhyay, A.; Sharma, A.; Chattopadhyay, S. J. Org. Chem. 2012, 77, 11064-11070. doi:10.1021/jo3020775

40. Goswami, D.; Koli, M. R.; Chatterjee, S.; Chattopadhyaya, S.; Sharma, A. Org. Biomol. Chem. 2017, 15, 3756-3774. doi:10.1039/C7OB00626H

41. Dey, P.; Koli, M.; Goswami, D.; Sharma, A.; Chattopadhyay, S Eur. J. Org. Chem. 2018, 1333-1341. doi:10.1002/ejoc.201800043

42. Chattopadhyay, A. J. Org. Chem. 1996, 61, 6104-6107. doi:10.1021/jo9604696

43. Lichtenberg, C.; Pan, F.; Spaniol, T. P.; Englert, U.; Okuda, J. Angew. Chem., Int. Ed. 2012, 51, 13011-13015. doi:10.1002/anie.201206782

\section{License and Terms}

This is an Open Access article under the terms of the Creative Commons Attribution License (http://creativecommons.org/licenses/by/4.0). Please note that the reuse, redistribution and reproduction in particular requires that the authors and source are credited.

The license is subject to the Beilstein Journal of Organic Chemistry terms and conditions: (https://www.beilstein-journals.org/bjoc)

The definitive version of this article is the electronic one which can be found at: doi:10.3762/bjoc. 14.193 